\title{
The optimization of extraction process of white mulberry leaves and the characteristic bioactive properties its powder extract
}

\author{
KRZYSZTOF PRZYGOŃSKI, ELŻBIETA WOJTOWICZ*
}

\author{
Department of Food Concentrates and Starch Products \\ Prof. Wacław Dąbrowski Institute of Agricultural and Food Biotechnology \\ Starołęcka 40 \\ 61-361 Poznań, Poland \\ "corresponding author: phone +48618 731 989, e-mail: elzbieta.wojtowicz@ibprs.pl
}

\section{Summary}

Introduction: Powder extracts from white mulberry leaves (Morus alba L.) are desirable due to their simplicity of use. Powders intended for use in food and dietary supplements can be obtained by various methods, including water extraction and spray drying.

Objective: The aim of the work was to optimize the aqueous process of extraction of white mulberry leaves and characterization of bioactive properties of the obtained extract powder.

Methods: The DNJ and flavonoids (quercetin, kaempferol) contents and were analysed by high performance liquid chromatography (HPLC). Total phenolic contents were determined using the Folin-Ciocalteu phenol reagent and antioxidant activity by ABTS and DPPH assays.

Results: The mulberry leaf extraction process has been optimized. The obtained powdered mulberry leaf extract proved to be a good source of bioactive compounds. Characteristic phenolic compounds detected in mulberry leaves and their powder extract were quercetin and kaempferol. The sum of polyphenols was 10.9 mg GAE/g dry matter in the raw material, whereas in the powder extract $42.6 \mathrm{mg} \mathrm{GAE} / \mathrm{g}$ dry matter. In addition, it was found that the obtained powdered extract is characterized by a five-fold higher, in comparison to the raw material, the content of antioxidant activity measured by ABTS and DPPH tests. The content of 1-deoxynojirimycin (DNJ) in the powder extract was nearly four times higher than in dry mulberry leaves.

Conclusion: The optimized process of water extraction of white mulberry leaves allows to keep valuable bioactive components and to obtain their high concentration.

Key words: Mulberry leaves extract, 1-deoxynojirimycin (DNJ), antioxidant activity, flavonoids

Słowa kluczowe: liście morwy białej, DNJ - 1,5-dideoksy-1,5-imino-D-sorbitol, aktywność antyoksydacyjna, flawonoidy 


\section{INTRODUCTION}

White mulberry (Morus alba L.) is a small deciduous tree belonging to the family of Moraceae. It is mainly appreciated because of its leaves, which are food for silkworm larvae producing natural silk. In Chinese medicine, mulberry leaves have been known for centuries as a medicinal product used in the form of infusions and decoctions. Recent studies show that both the leaves and extracts from the leaves of the white mulberry are a rich source of polyphenol antioxidants such as phenolic acids and flavonoids [1-4]. Besides the antioxidant properties, polyphenolic compounds have also positive effects on human health [5]. Mulberry and mulberry leaves extracts possess, among others, hypoglycaemic, hypolipidaemic, hypotensive, and diuretic properties [6-9]. The leaves and leaves extracts are also rich in naturally occurring alkaloid 1-deoxynojirimycin (DNJ) which is known to be a strong $\alpha$-glucosidase inhibitor [10, $11]$. DNJ inhibits $\alpha$-glycosidase by binding to its active site decreasing of glucose absorption and sugar level in blood.

There is still lack of studies reporting on any bioactive compounds extracted from $M$. alba and presenting the impact of extraction and spray drying process on DNJ and bioactive polyphenol content. Powdered extracts from M. alba are desirable for consumption apart from their simplicity in use. The common method of powder production is spray drying.

Thus, the aim of the work was to optimize the aqueous process of extraction of white mulberry leaves (M. alba) and characterization of bioactive properties of the obtained extract powder.

\section{MATERIAL AND METHODS}

\section{Raw material}

The material for the study were the leaves of white mulberry (Morus alba L.) harvested from the experimental plant farm (Institute of Natural Fibres and Medicinal Plants, Poznań, Poland). The leaves were washed and then dried in a convection dryer (Rational CCC $61 / 02$, Germany) at $60 \pm 1^{\circ} \mathrm{C}$ for $6-8 \mathrm{~h}$. The dried material was ground into powder and sieved. The $0.8-0.08 \mathrm{~mm}$ particles size were collected and stored in an air-tight container at $4 \pm 1^{\circ} \mathrm{C}$ until further use.

\section{Standards and reagents}

The following standards were used: 1-deoxynojirimycin hydrochloride, trolox, gallic acid, quercetin, kaempferol all from Sigma-Aldrich (Steinheim, Germany). Acetonitrile, glacial acetic acid, hydrochloric acid, ethanol, acetone, methanol, formic acid, sodium carbonate, and boric acid were purchased from POCH (Gliwice, Poland). Sodium tetraborate decahydrate, potassium persulfate, 9-fluorenylmethyl chloramate (FMOC-Cl), glycine, Folin-Ciocalteu's phenol reagent (FC reagent), 2,2-diphenyl-1-picrylhydrazyl (DPPH), 2,2'-azinobis(3-ethylbenzothiazoline-6-sulfonic acid) diammonium salt (ABTS), were purchased from SigmaAldrich (Steinheim, Germany). All reagents were of analytical or HPLC grade. The water used throughout the experiment was purified using a TKA Pacific system UP/UPW (Niederelbert, Germany).

\section{Extraction, concentration and spray drying of extracts from mulberry leaves}

First, the processes on laboratory scale were conducted. White mulberry leaves were extracted with water using laboratory shaker equipped with thermoregulator. The influence of temperature $\left(60,75,90^{\circ} \mathrm{C}\right)$, time $(30,60,90 \mathrm{~min})$ and $\mathrm{pH}(2,3,6)$ were analysed and the most optimal parameters were chosen. The concentration process was performed using laboratory vacuum evaporator (SPE type 350, Unipan, Poland) at a pressure of $0.6-0.8 \mathrm{~atm}$ and at $70-80^{\circ} \mathrm{C}$ until the 25-30\% dry matter in extract was achieved.

When the most appropriate parameters of extraction were established, the industrial extraction process on the semi-technical scale was performed. White mulberry leaves were extracted by $60 \mathrm{~min}$ in counter flow with water at $90 \pm 5^{\circ} \mathrm{C}$ and $\mathrm{pH}$ $6.0 \pm 0.5(1: 10 \mathrm{~m} / \mathrm{v})$ using a twin-screw continuous extractor (MPR Martin Plowens, Poland). Process yield: $10-15 \mathrm{~kg} / \mathrm{h}$. Then the aqueous extract was concentrated to about $30 \%$ of dry mass. Concentrating the aqueous extract was made periodically, using a vacuum evaporator WAA 20 („PEFA” Pleszew, Poland) at $70-80^{\circ} \mathrm{C}$ for 10 hours at a pressure of $0.6-0.8 \mathrm{~atm}$. Spray drying an concentrated aqueous extract was then performed using a spray dryer (Niro Atomizer SR16, Denmark). The yield of the dryer was $16 \mathrm{~kg}$ of evaporated water per hour. Drying was carried out with hot air in counter flow. Inlet air temperature was $\left(180 \pm 5^{\circ} \mathrm{C}\right)$ and outlet $\left(90 \pm 5^{\circ} \mathrm{C}\right)$. 


\section{1-deoxynojirmicine (DNJ) determination}

Qualitative and quantitative analysis of 1-deoxynojirmicine (DNJ) was performed by the modified method proposed by Kim and co-authors [12]. Sample $(250 \mathrm{mg})$ was extracted with $10 \mathrm{ml}$ of aqueous $0.05 \mathrm{M} \mathrm{HCl}$, next vigorously was shaken (approx. $15 \mathrm{~s}$ ) and centrifuged (4000 rpm) for $15 \mathrm{~min}$. The extract solution over the residue was saved and the residue was re-extracted again as described above. First and second extracts were transferred to the $25 \mathrm{ml}$ volumetric flask and filled with water. Then, obtained extracts were diluted with water $(1: 10 v / v)$ and used for derivatization. $100 \mu \mathrm{l}$ of DNJ standard or extract was mixed with $100 \mu \mathrm{l}$ of $0.4 \mathrm{M}$ potassium borate buffer $(\mathrm{pH} 8.5$ ) in a test tube. Then, $200 \mu \mathrm{l}$ of $5 \mathrm{mM}$ FMOC-Cl in acetonitrile was added with immediate mixing and allowed to react at $20^{\circ} \mathrm{C}$ for $20 \mathrm{~min} .100 \mu \mathrm{l}$ of $0.1 \mathrm{M}$ glycine was added to terminate the reaction. The mixture was diluted with $9.5 \mathrm{ml}$ of $0.1 \%(v / v)$ aqueous acetic acid, and filtered through a $0.45 \mu \mathrm{m}$ nylon syringe filter. The measurement of DNJ was performed using Dionex HPLC system (Dionex Corp., CA, USA). The chromatographic separation was on a Supelco Discovery C18 HS column ( $3 \mu \mathrm{m}, 150 \times 4.6 \mathrm{~mm}$ i.d.) (St. Louis, MO, USA) operated at $30^{\circ} \mathrm{C}$. The analyte was eluted with mobile phase of $0.1 \%$ aqueous acetic acid and acetonitrile $(60: 40, v / v)$ at $1 \mathrm{ml} / \mathrm{min}$ for $8 \mathrm{~min}$. After each analysis column was washing with acetonitrile by $5 \mathrm{~min}$ to remove impurities, and then conditioned with mobile phase by $5 \mathrm{~min}$. The injection volume was $10 \mu \mathrm{l}$. DNJ alkaloid was identificated using fluorescence detector Dionex RF 2000 (excitation 254 nm, emission $322 \mathrm{~nm}$ ). The concentration of mulberry DNJ was calculated from the calibration curve for standard DNJ. Regression coefficient for standard curve prepared in the range of $1-20 \mu \mathrm{g} / \mathrm{ml}$ was $\mathrm{R}^{2}=0.9994$. With the signal to noise ratio 3:1 detection limits were $0.14 \mu \mathrm{g} / \mathrm{ml}$.

\section{Total phenolic content and antioxidant activity determination}

\section{Extraction step}

The dry and grounded leaves of mulberry and powder extract $(0.5 \mathrm{~g})$ were weighted into a test tube and then extracted with $10 \mathrm{ml}$ of solvent $(70 \%$ aqueous acetone). Tube was shaken at room temperature for $60 \mathrm{~min}$. Then, samples were centrifuged (4000 rpm) for $10 \mathrm{~min}$. The clear supernatant was collected. The procedure was repeated with $10 \mathrm{ml}$ of solvent $(70 \%$ aqueous methanol). Both collected supernatants were transferred to the $25 \mathrm{ml}$ volumetric flask and filled with methanol. Extracts were stored at $4 \pm 1^{\circ} \mathrm{C}$ until analysis.

\section{The total phenolic content (TP)}

The total phenolic content (TP) were estimated by the modified method of Singleton and Rossi [13] using FC reagent. The $0.5 \mathrm{ml}$ extract solution was mixed with $2.5 \mathrm{ml}$ of $\mathrm{FC}$ reagent (pre-diluted 10 times with distilled water). After standing for $6 \mathrm{~min}$ at room temperature, $2 \mathrm{ml}$ of $7.5 \%$ sodium carbonate solution were added, then mixed and allowed to stand for $60 \mathrm{~min}$ at room temperature in darkness. Then the absorbance was read at $765 \mathrm{~nm}$ using a UV-visible spectrophotometer (UV/VIS Philips PU 8735, Great Britain). A calibration curve was prepared, using a standard solution of gallic acid (from 10 to $100 \mathrm{mg} / \mathrm{ml}$ ). Results were expressed as $\mathrm{mg}$ gallic acid equivalent (GAE).

\section{DPPH free radical scavenging activity}

2,2-Diphenyl-1-picrylhydrazyl radical (DPPH•) assay was carried out to measure the free radical scavenging activity as described previously by Nuutila et al. [14]. The $3.0 \mathrm{ml}$ of $0.1 \mathrm{mM} \mathrm{DPPH}$ solution in methanol (between 0.8-0.9 absorbance units) was mixed with $0.1 \mathrm{ml}$ extract solution or standard solution (Trolox). After mixing, the tubes were incubated in darkness for $60 \mathrm{~min}$ at a room temperature. Then the absorbance was read at $520 \mathrm{~nm}$ using a spectrophotometer (UV/VIS Philips PU 8735, Great Britain). Results were expressed in mg Trolox equivalents (TxE).

\section{ABTS free radical scavenging activity}

Radical scavenging activity of mulberry leaves extracts was measured according to Re et al. [15]. Trolox Equivalent antioxidant capacity was determined by the decolorization $\mathrm{ABTS}^{*+}$ in comparison to Trolox standard. Briefly, potassium persulfate solution was mixed with ABTS solution in order to generate blue-green $\mathrm{ABTS}^{*+}$. The mixture was incubated in darkness for $16 \mathrm{~h}$. Then, the formed solution was diluted with ethanol until the initial 
absorbance value of 0.7 at $735 \mathrm{~nm}$ was reached. For the evaluation, $3 \mathrm{ml}$ of diluted $\mathrm{ABTS}^{*+}$ solution was added to $30 \mu \mathrm{l}$ of antioxidant extract (as described above) or Trolox standard, and then the mixture was vigorously shaken for $30 \mathrm{~s}$. After $20 \mathrm{~min}$ incubation in the dark the mixture was poured into cuvettes $(1 \mathrm{~cm} \mathrm{x} 1 \mathrm{~cm} \times 3.5 \mathrm{~cm})$ and then the absorbance was read at $735 \mathrm{~nm}$, using a spectrophotometer. Results were expressed in mg Trolox equivalents (TxE).

\section{Sample preparation, identification and quanti- fication of flavonoids}

Standard solutions of different flavonoids were prepared by dissolving $10 \mathrm{mg}$ of standard in $10 \mathrm{ml}$ of methanol individually. The extraction process was carried out identically as described above. The evaluation of qualitative and quantitative composition of flavonoids according to the procedure based on the modified Hertog et al. [16] was done. $4 \mathrm{ml}$ of clear extract and $0.6 \mathrm{ml}$ of $6 \mathrm{M}$ hydrochloric acid was added to a $25 \mathrm{ml}$ test tube, then the air was removed from nitrogen, the tube was sealed and heated in $90 \pm 1^{\circ} \mathrm{C}$ by 1 hour. After cooling, the hydrolyzate was transferred to a $5 \mathrm{ml}$ volumetric flask and filled up with water to the mark. Then, the solution was filtered through a $0.45 \mu \mathrm{m}$ nylon syringe filter and subjected to chromatographic separation.

The chromatographic analysis of flavonoids was based on the modified method described by Sakakibara et al. [17]. The measurement of flavonoids was performed using Dionex HPLC system (Dionex Corp., CA, USA). Chromatographic separation was performed on a reversed phase column Supelco Ascentis C18 (5 $\mu \mathrm{m}, 250$ x $4.6 \mathrm{~mm})$ (St. Louis, MO, USA). The column temperature was set at $30^{\circ} \mathrm{C}$. A linear gradient elution system, using solvent $\mathrm{A}: 0.1 \%$ formic acid in water - methanol mixture $(75: 25 v / v)$ and $\mathrm{pH} 2.7$ and solvent B: $0.1 \%$ formic acid in water-methanol mixture $(20: 80 v / v)$ according to the following profile: from 0 to $100 \%$ B (0-1 $\mathrm{min} / 0 \% \mathrm{~B}, 1-31 \mathrm{~min} / 0-100 \% \mathrm{~B}$, 31-33 $\mathrm{min} / 100-0 \% \mathrm{~B}, 33-35 \mathrm{~min} / 0 \% \mathrm{~B}$ ). The flow rate was maintained constant at $1 \mathrm{ml} / \mathrm{min}$. The sample injection volume was $20 \mu \mathrm{l}$.

The compounds present in each sample were identified by comparing their retention times and UV-visible spectra obtained from the PAD detector-100 (Dionex Photodiode Array Detektor) with those of standards.
Ethical approval: The conducted research is not related to either human or animal use.

\section{RESULTS AND DISCUSSION}

Tables 1-3 present the effect of time, temperature and $\mathrm{pH}$ on the efficiency of extraction. The results of the studies on the impact of the extraction time on individual separators are presented in table 1. It was found that the influence of the extraction time on the DNJ content, the results of antioxidative tests and the content of main phenolic compounds: quercetin and kaempferol had a slight effect. The extraction time of 60 min was selected for further experiments. Then, the influence of the extraction temperature on its efficiency was examined (tab. 2) and it was found that the best effect was achieved at $90^{\circ} \mathrm{C}$. At the next stage of the research, the impact of $\mathrm{pH}$ on the extract yield was evaluated (tab. 3).

The results of all the indicators shown that the extraction was carried at the best out in $\mathrm{pH}$ 6. Mulberry leaves were extracted at the determined optimal parameters and raw material and the obtained dry extract was characterized and collected in table 4. The content of DNJ in raw material (dry mulberry leaves) amounted $1.03 \mathrm{mg} / \mathrm{g}$ DM. Sample chromatogram is shown in (fig. 1). Our results were in the range obtained by Vichasilp et al. [11] whose demonstrated that DNJ concentration in young mulberry leaves varied among mulberry varieties from 30 to $170 \mathrm{mg} / 100 \mathrm{~g}$ of dry leaves. Hu et al. [18] presented that in 58 varieties of $M$. alba the range of DNJ concentration varied from 0.1341 to $1.472 \mathrm{mg} / \mathrm{g}$ of dry leaf. In comparisons to Song et al. [19], who reported that DNJ content in dried mulberry leaves of 33 cultivars varied between $1.389-3.483 \mathrm{mg} / \mathrm{g}$ in dependent on the mulberry variety, ours results were located near the lower limits. The use of an aqueous extraction process caused a significant $(p<0.05)$, near then fourfold increase of this compound in obtained powder extract in comparison with raw material, it was $3.45 \mathrm{mg} / \mathrm{g}$ DM.

The total polyphenolic content (TP) in the powdered extract was fourfold higher than in dry leaves and amounted respectively $42.6 \mathrm{mg}$ GAE/g DM. The values of TP in dry leaves was $10.9 \mathrm{mg} \mathrm{GAE} / \mathrm{g}$ DM. Total polyphenolic content in mulberry leaves was in agreement with results of Lee et al. [20], but threefold lower in comparison with the six mulberry cultivars from China ranged from [21]. Lower concentration of TP in 


\section{Table 1}

Influence of extraction time (water: temperature extraction, $60^{\circ} \mathrm{C} ; \mathrm{pH}$ ) on DNJ, antioxidant activity (ABTS, DPPH), flavonoids and total phenolics content in white mulberry powder extract

\begin{tabular}{lllllll}
\hline $\begin{array}{l}\text { Extraction } \\
\text { time }\end{array}$ & DNJ & ABTS & DPPH & TP & quercetin & kaempferol \\
\hline min. & {$[\mathrm{mg} / \mathrm{g} \mathrm{DM}]$} & {$[\mathrm{mg} \mathrm{TxE} / \mathrm{g} \mathrm{DM}]$} & {$[\mathrm{mg} \mathrm{TxE} / \mathrm{g} \mathrm{DM}]$} & {$[\mathrm{mg} \mathrm{GAE} / \mathrm{g} \mathrm{DM}]$} & {$[\mathrm{mg} / \mathrm{g} \mathrm{DM}]$} & {$[\mathrm{mg} / \mathrm{g} \mathrm{DM}]$} \\
\hline 30 & $0.68 \pm 0.01$ & $35.4 \pm 0.9$ & $19.8 \pm 0.2$ & $12.6 \pm 0.1$ & $1.45 \pm 0.06$ & $0.50 \pm 0.02$ \\
\hline 60 & $0.73 \pm 0.01$ & $37.1 \pm 0.2$ & $20.9 \pm 0.1$ & $12.9 \pm 0.1$ & $1.27 \pm 0.05$ & $0.46 \pm 0.02$ \\
\hline 90 & $0.76 \pm 0.01$ & $35.7 \pm 0.2$ & $21.1 \pm 0.1$ & $12.7 \pm 0.1$ & $1.13 \pm 0.05$ & $0.42 \pm 0.02$ \\
\hline
\end{tabular}

Results are presented as means \pm standard deviation, $\mathrm{n}=3$.

DNJ -1 - deoxynojirmicine; DM - dry mass; ABTS - 2,2'-azino-bis (3-ethylbenzothiazoline-6-sulfonic acid); DPPH 2,2-diphenyl-1-picrylhydrazyl; TxE - Trolox equivalents - 6-hydroxy-2,5,7,8-tetramethylchroman-2-carboxilic acid; GAE gallic acid equivalents

\section{Table 2}

Influence temperature extraction (water: time $60 \mathrm{~min}, \mathrm{pH}$ 6) on DNJ on antioxidant activity (ABTS, DPPH), flavonoids and total phenolics content in white mulberry extract

\begin{tabular}{lllllll}
\hline $\begin{array}{l}\text { Extraction } \\
\text { temperature }\end{array}$ & DNJ & ABTS & DPPH & TP & quercetin & kaempferol \\
\hline${ }^{\circ} \mathrm{C}$ & {$[\mathrm{mg} / \mathrm{g} \mathrm{DM}]$} & {$[\mathrm{mg} \mathrm{TxE} / \mathrm{g} \mathrm{DM}]$} & {$[\mathrm{mg} \mathrm{TxE} / \mathrm{g} \mathrm{DM}]$} & {$[\mathrm{mg} \mathrm{GAE} / \mathrm{g} \mathrm{DM}]$} & {$[\mathrm{mg} / \mathrm{g} \mathrm{DM}]$} & {$[\mathrm{mg} / \mathrm{g} \mathrm{DM}]$} \\
\hline 60 & $0.73 \pm 0.01$ & $37.1 \pm 0.2$ & $20.9 \pm 0.1$ & $12.9 \pm 0.1$ & $1.27 \pm 0.05$ & $0.46 \pm 0.02$ \\
\hline 75 & $1.05 \pm 0.02$ & $38.0 \pm 2.9$ & $20.3 \pm 0.1$ & $13.7 \pm 0.1$ & $1.31 \pm 0.06$ & $0.46 \pm 0.02$ \\
\hline 90 & $1.21 \pm 0.02$ & $44.3 \pm 2.7$ & $27.4 \pm 0.4$ & $15.3 \pm 0.1$ & $1.45 \pm 0.06$ & $0.48 \pm 0.02$ \\
\hline
\end{tabular}

Results are presented as means \pm standard deviation, $\mathrm{n}=3$.

DNJ -1 - deoxynojirmicine; DM - dry mass; ABTS - 2,2'-azino-bis (3-ethylbenzothiazoline-6-sulfonic acid); DPPH -

2,2-diphenyl-1-picrylhydrazyl; TxE - Trolox equivalents - 6-hydroxy-2,5,7,8-tetramethylchroman-2-carboxilic acid; GAE gallic acid equivalents

Table 3

Influence of $\mathrm{pH}$ extraction (water: temperature $90^{\circ} \mathrm{C}$; time $60 \mathrm{~min}$ ) on DNJ, antioxidant activity (ABTS, DPPH), flavonoids and total phenolics content in white mulberry extract

\begin{tabular}{lllllll}
\hline Extraction $\mathrm{pH}$ & $\mathrm{DNJ}$ & $\mathrm{ABTS}$ & $\mathrm{DPPH}$ & $\mathrm{TP}$ & quercetin & kaempferol \\
\hline $\mathrm{pH}$ & {$[\mathrm{mg} / \mathrm{g} \mathrm{DM}]$} & {$[\mathrm{mg} \mathrm{TxE} / \mathrm{g} \mathrm{DM}]$} & {$[\mathrm{mg} \mathrm{TxE} / \mathrm{g} \mathrm{DM}]$} & {$[\mathrm{mg} \mathrm{GAE} / \mathrm{g} \mathrm{DM}]$} & {$[\mathrm{mg} / \mathrm{g} \mathrm{DM}]$} & {$[\mathrm{mg} / \mathrm{g} \mathrm{DM}]$} \\
\hline 6 & $1.21 \pm 0.02$ & $44.3 \pm 2.7$ & $27.4 \pm 0.4$ & $15.3 \pm 0.1$ & $1.45 \pm 0.06$ & $0.48 \pm 0.02$ \\
\hline 3 & $1.15 \pm 0.02$ & $41.2 \pm 0.4$ & $25.0 \pm 0.4$ & $13.9 \pm 0.1$ & $1.16 \pm 0.05$ & $0.41 \pm 0.02$ \\
\hline 2 & $0.65 \pm 0.01$ & $21.8 \pm 0.1$ & $13.6 \pm 0.5$ & $13.1 \pm 0.1$ & $1.87 \pm 0.08$ & $0.52 \pm 0.02$ \\
\hline
\end{tabular}

Results are presented as means \pm standard deviation, $\mathrm{n}=3$.

DNJ -1 - deoxynojirmicine; DM - dry mass; ABTS - 2,2'-azino-bis (3-ethylbenzothiazoline-6-sulfonic acid); DPPH 2,2-diphenyl-1-picrylhydrazyl; TxE - Trolox equivalents - 6-hydroxy-2,5,7,8-tetramethylchroman-2-carboxilic acid; GAE gallic acid equivalents

Table 4

The characteristic of mulberry dry leaves and dried powder extract (water extraction, time $60 \mathrm{~min}$, temp. $90^{\circ} \mathrm{C}$, $\mathrm{pH} 6$ )

\begin{tabular}{llllllll}
\hline Mulberry & moisture & DNJ & ABTS & DPPH & TP & quercetin & kaempferol \\
\hline $\mathrm{pH}$ & {$[\%]$} & {$[\mathrm{mg} / \mathrm{g} \mathrm{DM}]$} & {$[\mathrm{mg} \mathrm{TxE} / \mathrm{g} \mathrm{DM}]$} & {$[\mathrm{mg} \mathrm{TxE} / \mathrm{g} \mathrm{DM}]$} & {$[\mathrm{mg} \mathrm{GAE} / \mathrm{g} \mathrm{DM}]$} & {$[\mathrm{mg} / \mathrm{g} \mathrm{DM}]$} & {$[\mathrm{mg} / \mathrm{g} \mathrm{DM}]$} \\
\hline Dry leaves & $8.40 \pm 0.01$ & $1.03 \pm 0.01$ & $18.1 \pm 0.7$ & $24.5 \pm 2.3$ & $10.9 \pm 1.2$ & $2.12 \pm 0.20$ & $0.72 \pm 0.04$ \\
\hline Powder extract & $2.40 \pm 0.01$ & $3.45 \pm 0.08$ & $97.9 \pm 3.8$ & $124.3 \pm 8.1$ & $42.6 \pm 0.3$ & $1.87 \pm 0.06$ & $0.83 \pm 0.06$ \\
\hline
\end{tabular}

DNJ -1-deoxynojirmicine; DM - dry mass; ABTS - 2,2'-azino-bis (3-ethylbenzothiazoline-6-sulfonic acid); DPPH 2,2-diphenyl-1-picrylhydrazyl; TxE - Trolox equivalents - 6-hydroxy-2,5,7,8-tetramethylchroman-2-carboxilic acid; GAE gallic acid equivalents 
a

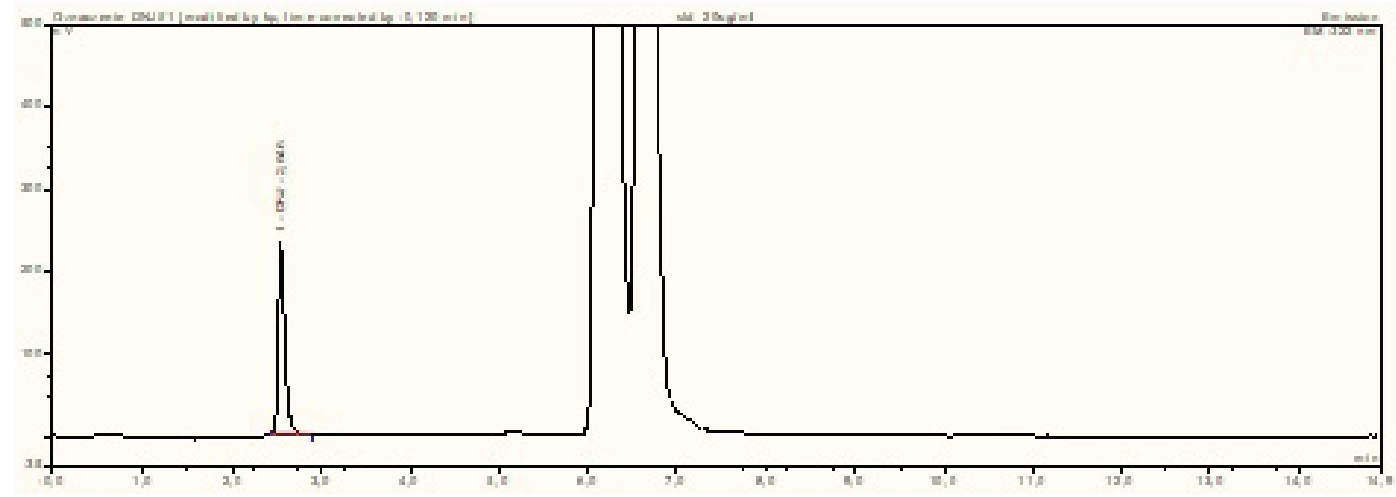

b

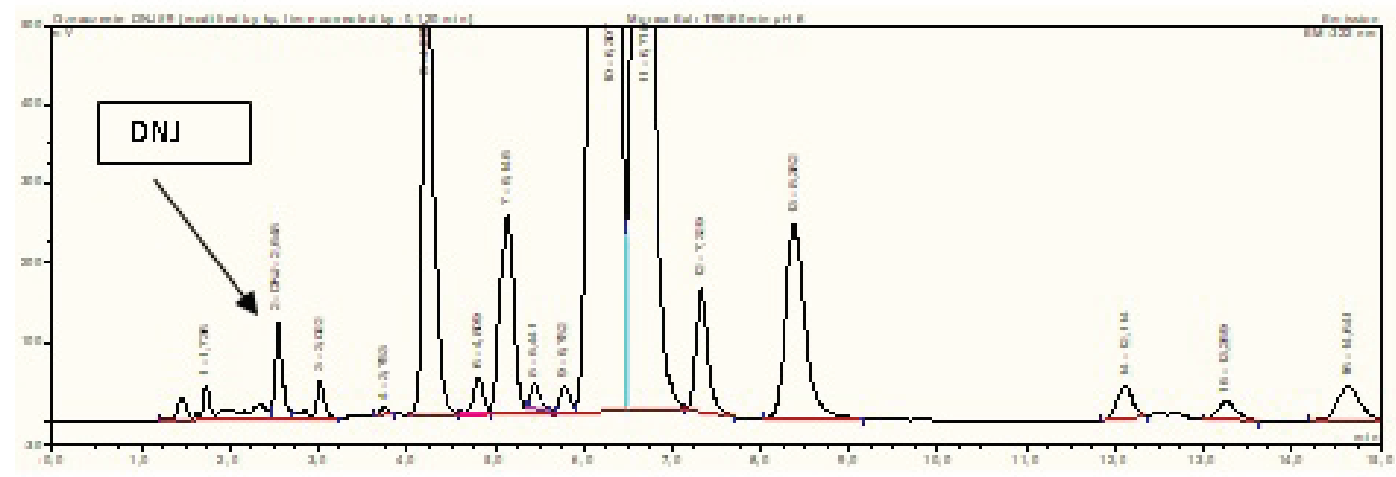

Figure 1

HPLC chromatogram of (a): standard 1-deoxynojirimycin (DNJ) $(20 \mu \mathrm{g} / \mathrm{ml})$ (b) DNJ extracted from mulberry leaves

comparison to Zou [21] could be due the drying process. As reported Wanyo [22] thermal processing have both adverse and favourable effects on TP. Losses in TP by thermal processing have been also reported by Tan [22] who showed that drying process above $50^{\circ} \mathrm{C}$ effects on degradation of phenolic compounds in mulberry leaves. Also Jeszka [7] received two times higher concentration of TP in extract from M. alba from Polish variety which was $9.26 \mathrm{~g} \mathrm{GAE} / 100 \mathrm{~g}$ DM using acetonewater $(65: 35 v / v)$ extraction at $54^{\circ} \mathrm{C}$. In the current study extraction was done with water which was found to be much safer, but less effective solvent for the extraction of TP from mulberry leaves in comparison with acetone and methanol [23] what may influence on lower results. However, it should be noted that aqueous extraction is much safer in application to food products as compared to the acetone-water extraction.

There were two flavonoids (quercetin, and kaempferol) in the mulberry leaves and leaves powder extract analysed (tab. 1-4). The quercetin concentration varied from $2.12 \mathrm{mg} / \mathrm{g} D M$ in leaves to $1.87 \mathrm{mg} / \mathrm{g} D M$ in powdered extract. The kaempferol concentration varied from $0.72 \mathrm{mg} / \mathrm{g}$ $\mathrm{DM}$ in leaves to $0.83 \mathrm{mg} / \mathrm{g} \mathrm{DM}$ in powdered extract. Decrease of flavonoids content in obtained extracts in comparison with raw material may be due their low solubility in water. Research Katsube et al. $[2,3]$ in ethanol extracts showed the presence of quercetin and kaempferol glycosides, the content of main glycosides quercetin 3-(6-malonylglucoside) and kaempferol 3-(6-malonylglycoside) was respectively $900 \mathrm{mg} / 100 \mathrm{~g}$ and $192 \mathrm{mg} / 100 \mathrm{~g}$. Research Thabti et al. [4] of methanol extract from mulberry leaves confirmed the significant content of glycosides of quercetin and kaempferol in this plant product. Dry mulberry leaves exhibited DPPH radical scavenging activity as $18.1 \mathrm{mg} \mathrm{TE} / \mathrm{g}$ DM. This agrees with a recent study of SánchezSalcedo et al. [25] showing slightly lower radical scavenging activity amounting till $12.64 \mathrm{mg}$ TxE/g DW. The water extraction process caused more than fivefold increase of antioxidant activity. These results are in line with other studies reporting a similar DPPH radical scavenging activity in acetone-water and ethanol-water extracts, which amounted respectively $35.28 \mathrm{mmol} \mathrm{TxE} / 100 \mathrm{~g}$ of 
DM and $38.81 \mathrm{mmol}$ TxE/100 g [7]. Dry mulberry extract had also the highest capacity to reduce the ABTS radical cation than dry mulberry leaves. It amounted $124.3 \mathrm{mg}$ TxE/g DM. The capacity to reduce the ABTS radical cation in mulberry powder extract received by water extraction was sevenfold higher than in M. alba ethanol-water extract presented by Jeszka-Skowron et al. [7] who reported $7.23 \mathrm{mM} \mathrm{TxE} / 100 \mathrm{~g}$ of DM.

\section{CONCLUSION}

The extraction process, in optimized extraction parameters, caused about fivefold increase, in comparison to raw material, antioxidant activity measured using $\mathrm{ABTS}$ and $\mathrm{DPPH}$ tests despite the flavonols such as quercetin was slightly reduced. DNJ content in the powder extract was four times higher than in dry mulberry leaves. The optimized process of water extraction of the white mulberry leaves allows to keep valuable bioactive components and achieve their high concentration.

Conflict of interest: Authors declare no conflict of interest.

\section{REFERENCES}

1. Butt MS, Nazira A, Sultan MT, Schroen K. Morus alba L. nature's functional tonic. Trends Food Sci Technol 2008; 19:505-512.

2. Katsube T, Imawaka N, Kawano Y, Yamazaki Y, Shiwaku K, Yamane Y. Antioxidant flavonol glycosides in mulberry (Morus alba L.) leaves isolated based on LDL antioxidant activity. Food Chem 2006; 97:25-31. doi: http://dx.doi. org/10.1186/1472-6882-14-139

3. Katsube T, Yamasaki M, Shiwaku K, Ishijima T, Matsumoto I, Abe K, Yamasaki Y. Effect of flavonol glycoside in mulberry (Morus alba L.) leaf on glucose metabolism and oxidative stress in liver in diet-induced obese mice. J Sci Food Agric 2010; 90:2386-2392. doi: http://dx.doi.org/10.1002/ jsfa.4096

4. Thabti I, Elfalleh W, Hannachi H, Ferchichi A, Campos MG. Identification and quantification of phenolic acids and flavonol glycosides in $\mathrm{Tu}$ nisian Morus species by HPLC-DAD and HPLC-
MS. J Func Foods 2012; 4:367-374. doi: http:// dx.doi.org/10.1016/j.jff.2012.01.006

5. Halliwell B. Dietary polyphenols: good, bad, or indifferent for your health? Cardiovasc Res 2007; 73: 341-347. doi: http://dx.doi.org/10.1016/j.cardiores.2006.10.004

6. Chung HI, Kim J, Kim JY, Kwon O. Acute intake of mulberry leaf aqueous extract affects postprandial glucose response after maltose loading randomized double-blind placebo-controlled pilot study. J Func Foods 2013; 5:1502-1506.

7. Jeszka-Skowron M, Flaczyk E, Jeszka J, Krejpcio Z, Król E, Buchowski MS. Mulberry leaf extract intake reduces hyperglycaemia in streptozotocin (STZ)-induced diabetic rats fed high-fat diet. J Func Foods 2014; 8:9-17. doi: http://dx.doi. org/10.15193/zntj/2014/92/148-159

8. Liu LK, Chou FP, Chen YC, Chyau CC, Ho HH, Wang CJ. Effects of mulberry (Morus alba L.) extracts on lipid homeostasis in vitro and in vivo. J Agric Food Chem 2009; 57:7605-7611. doi: http://dx.doi.org/10.1021/jf9014697

9. Memon A, Memon N, Luthria D, Bhanger M, Pitafi A. Phenolic acids profiling and antioxidant potential of mulberry (Morus laevigata W., Morus nigra L., Morus alba L.) leaves and fruits grown in Pacistan. Pol J Food Nutr 2010, 60:25-32

10. Nuengchamnong $\mathrm{N}$, Ingkaninan $\mathrm{K}$, Kaewruang W, Wongareonwanakij S, Hongthongdaeng B. Quantitative determination of 1-deoxynojirimycin in mulberry leaves using liquid chromatography-tandem mass spectrometry. J Pharm Biomed Anal 2007; 44:853-858. doi: http://dx.doi. org/10.1016/j.jpba.2007.03.031

11. Vachasilp Ch, Nakagawa K, Sookwong P, Higuchi O, Kimura F. A novel gelatin crosslinking method retards release of mulberry 1-deoxynojirimycin providing a prolonged hypoglycaemic effect. Food Chem 2012; 134:1823-1830. doi: http:// dx.doi.org/10.1016/j.foodchem.2012.03.086

12. Kim J-W, Kim S-U, Lee HS, Kim I, Ahn MY, Ryu KS. Determination of 1-deoxynojirimycin in Morus alba L. leaves by derivatization with 9-fluorenylmethyl chloroformate followed by reversephase high-performance liquid chromatography. J Chromatogr A 2003; 1002:93-99. 
13. Singleton VL, Rossi JA. Colorimetry of total phenolics with phosphomolybdic - phosphotungstic acid reagents. Am J Enol Vitic 1965; 16:144-158. doi: http://dx.doi.org/10.3390/ijms11062362

14. Nuutila AM, Puupponen-Pimiä R, Aarni M, Oksman-Caldentey KM. Comparison of antioxidant activities of onion and garlic extracts by inhibition of lipid peroxidation and radical scavenging activity. Food Chem 2003; 81:485-493. doi: http:// dx.doi.org/10.1016/S0308-8146(02)00476-4

15. Re R, Pellegrini N, Proteggente A, Pannala A, Yang M, Rice-Evans C. Antioxidant activity applying an improved ABTS radical cation decolorization assay. Free Radi Bio Med 1999; 26: 12311237. doi: http.//dx. doi.org /10.1016/S08915849(98)00315-3

16. Hertog J, Pals CEGM, Jonk LJC, Kruijer W. Differential expression of a novel murine non-receptor protein tyrosine phosphatase during differentiation of P19 embryonal carcinoma cells. Biochem Biophys Res Commun 1992; 184:1241-1249. doi: http://doi.org/10.1016/S0006-291X(05)80015-4

17. Sakakibara H, Honda Y, Nakagawa S, Ashida H, Kanazawa K. Simultaneous determination of all polyphenols in vegetables, fruits, and teas. J Agric Food Chem 2003; 51:571-81. doi: http://dx.doi. org/10.1021/jf0209261

18. Hu X-Q, Jiang L, Zhang J-G, Deng W, Wang $\mathrm{H}-\mathrm{L}$, Wei Z-J. Quantitative determination of 1-deoxynojirimycin in mulberry leaves from 132 varieties. Ind Crop Prod 2013; 49:782-784. doi: http://dx.doi.org/10.1016/j.indcrop.2013.06.030

19. Song W, Wang HJ, Bucheli P, Zhang PF, Wei DZ, Lu YH. Phytochemical profiles of different mulberry (Morus sp.) species from China. J Agric Food Chem 2009; 57:9133-9140. doi: http:// dx.doi.org/10.1021/jf9022228
20. Lee NK, Jeong JH, Oh J, Kim Y, Ha YS, Jeong Y-S. Conversion of flavonols kaempferol and quercetin in mulberry (Morus alba L.) leaf using plant-fermenting lactobacillus plantarum. J Food Biochem 2015; 39: 765-770. doi: http://doi. org/10.1111/jfbc.12176

21. Zou Y, Liao S, Shen W, Liu F, Tang C, Chen CHYO, Sun Y. Phenolics and antioxidant activity of mulberry leaves depend on cultivar and harvest month in southern China. Int J Mol Sci 2012; 13:16544-16533. doi: http://dx.doi.org/10.3390/ ijms 131216544

22. Wanyo P, Siriamornpun S, Meeso N. Improvement of quality and antioxidant properties of dried mulberry leaves with combined far-infrared radiation and air convection in Thai tea process. Food Bioprod Process 2011; 89:22-30. doi: http://dx.doi.org/10.1016/j.fbp.2010.03.005

23. Tan JJY, Lim YY, Siow LF, Tan JBL. Effects of drying on polyphenol oxidase and antioxidant activity of Morus alba leaves. J Food Process Preserv 2015; 39:2811-2819. doi: http://dx.doi. org/10.1111/jfpp.12532

24. Arabshahi-Delouee S, Urooj A. Antioxidant properties of various solvent extracts of mulberry (Morus indica L.) leaves. Food Chem 2007; 102:1233-1240. doi: http://dx.doi.org/10.1016/j. foodchem.2006.07.013

25. Sánchez-Salcedo EV, Mena P, Garcia-Viguera C, Hernández F, Martinéz JJ. (Poly)phenolic compounds and antioxidant activity of white (Morus alba) and black (Morus nigra) mulberry leaves: Their potential for new products rich in phytochemicals. J Fun Foods 2015; 18:1039-1046. doi: http://dx.doi.org/10.1515/ fhort-2017-0023 